\title{
STATUS OF NEOTROPICAL MIGRANT SONGBIRDS IN MANITOBA - TIME FOR A SECOND LOOK
}

KEITH A. HOBSON, Canadian Wildlife Service, 115 Perimeter Road, Saskatoon, Saskatchewan. S7N 0X4

There is a growing awareness in Canada and throughout the world of the tremendous extent and possible consequences of deforestation in both tropical and temperate regions. While attention has been focused largely on aspects of climate change and the overwhelming loss of the world's biodiversity, fewer Canadians will be aware of the more immediate effects on local populations of breeding songbirds.

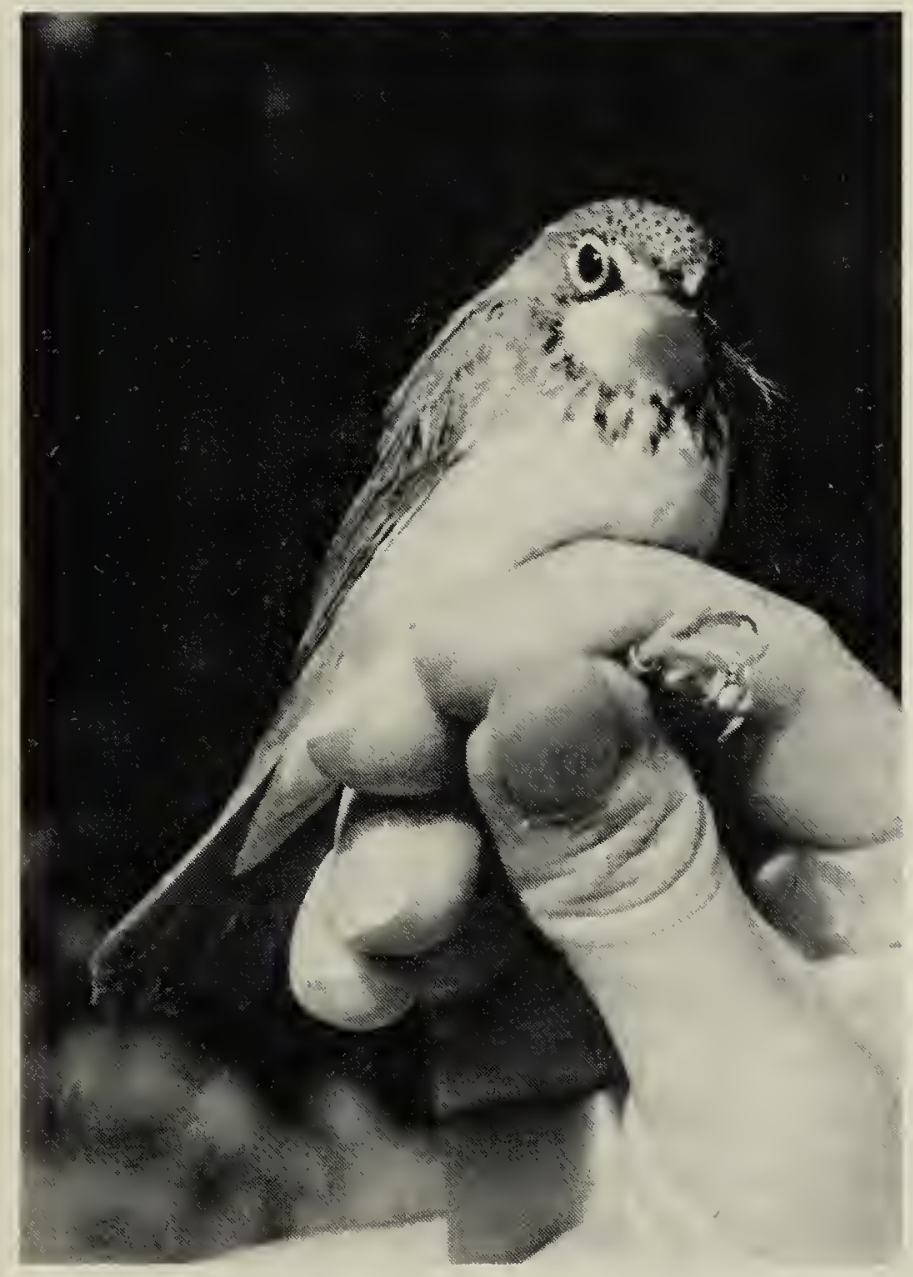

Canada Warbler banded at Delta, 8 September 1992.

Keith Hobson
Neotropical migrants, those birds breeding in the temperate regions of North America but who winter and indeed spend most of their lives in Central and South America or the Caribbean, are facing tremendous pressures from habitat loss. ${ }^{3,4,5}$ This pressure is in addition to a host of other, often related, factors such as predation, parasitism by Brownheaded Cowbirds and the widespread use of pesticides. ${ }^{2,5,6}$ Indeed, during the last decade, alarm bells have been ringing in the minds of scientists and naturalists alike as data indicating steady declines in several songbird populations accumulate. ${ }^{4}$ However, these trends are largely based on studies of populations of migrants that move through and breed in the hardwood forests of the eastern United States and it is generally not known to what extent populations of songbirds may be declining elsewhere throughout the continent. ${ }^{1,4}$

The vast majority of songbirds known to breed in the woodlots and forests of Canada winter south of the U.S.-Mexico border and are potentially at risk due to habitat change. Diamond estimated that 79 species of birds that breed in Canada winter only in the tropical forests of Central America and most of these can be found in the Canadian prairie provinces. ${ }^{3}$ Diamond's estimate included 27 species of warblers alone. 


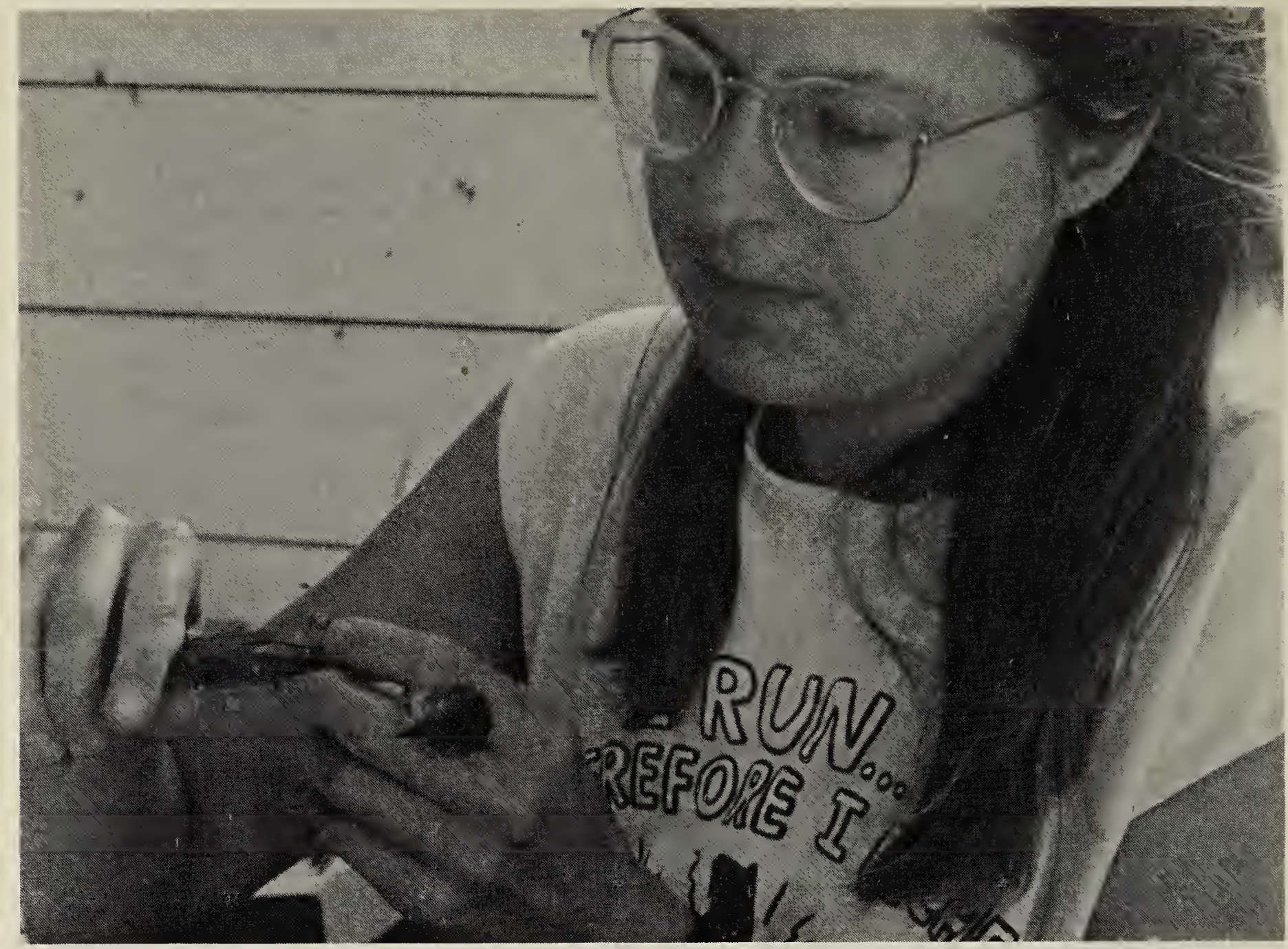

Enid Cumming banding a Magnolia Warbler at the Delta station.

Keith Hobson

Several methods have been used to monitor the populations of birds in North America. Many naturalists will be familiar with the roadside Breeding Bird Survey (BBS) sponsored jointly by the U.S. Fish and Wildlife Service and the Canadian Wildlife Service. This program provides an invaluable continent-wide analysis of the trends in populations of birds breeding north of Mexico but is necessarily restricted to regions that are accessible by car. Several BBS routes have been established on the Prairies but many more are needed to provide more adequate coverage in most regions. Banding stations, where birds are captured by mistnetting, also provide information on the status of migrant songbirds. Rather than being a technique to establish wintering grounds or migration routes through band recoveries, the banding of migrant songbirds is typically used to determine population status, survival and productivity of birds through constant-effort mistnet- ting. Ageing of birds through the examination of skull bone development and the evaluation of body condition by visually scoring the fat deposits around the neck and breast add tremendously to the value of mistnetting songbirds.

The paucity of data on populations of neotropical migrants occurring in the Prairies has prompted the Canadian Wildlife Service (CWS) to establish a monitoring station at Last Mountain Lake in Saskatchewan. Operated by Al Smith (CWS, Saskatoon) in spring and fall, it compliments similar efforts in Alberta, such as the Beaverhill Bird Observatory. Routine netting at these stations will help us establish the population status and reproductive success of some species but will not tell us how neotropical migrants may have declined historically in this region. Fortunately, a banding study conducted in the early 1980s has provided an 


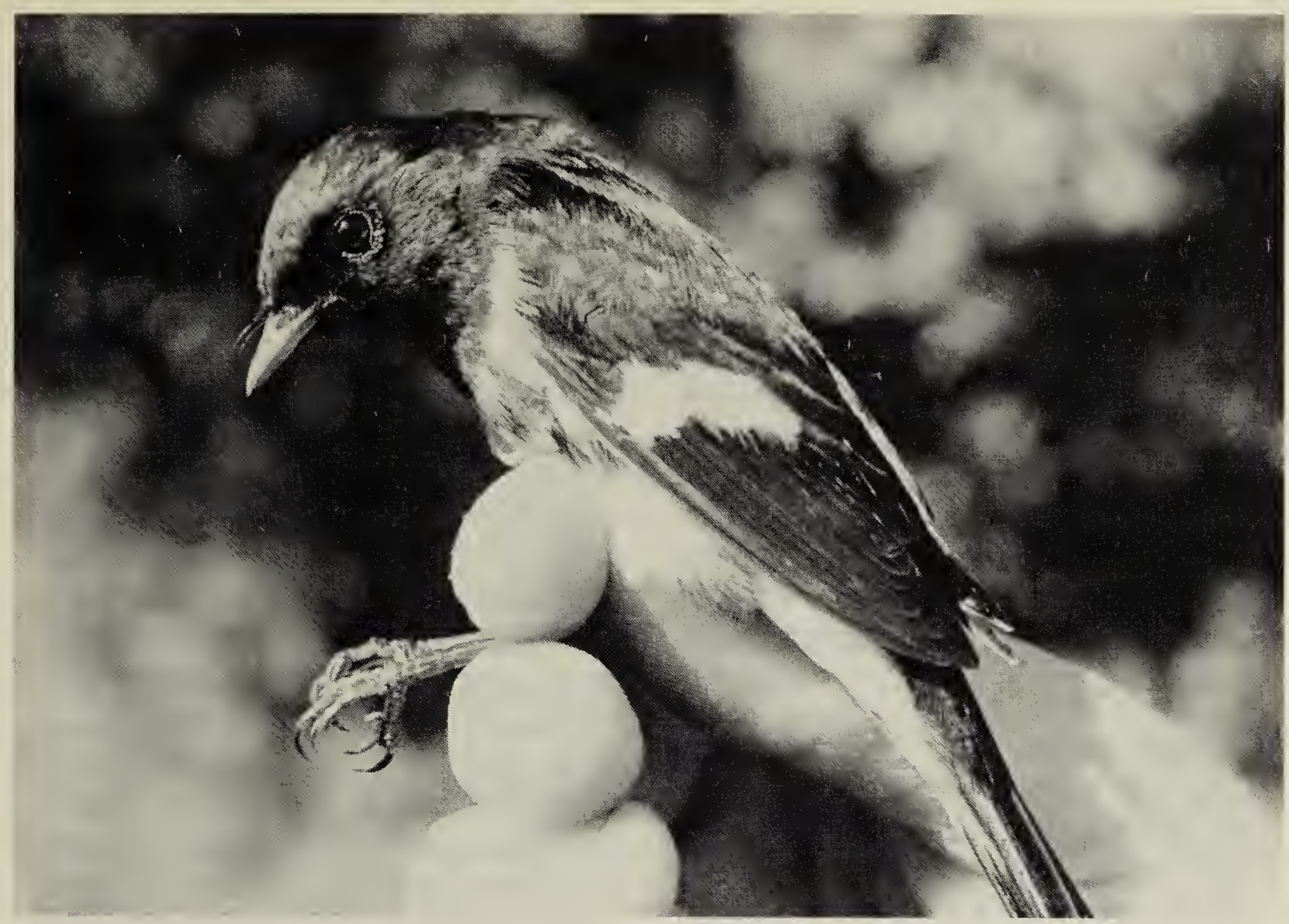

Adult male American Redstart banded at Delta, 15 September 1992.

Keith Hobson

excellent opportunity to monitor possible declines of warblers moving through south-central Manitoba.

From 1982 to 1984, Heidi den Haan, under the supervision of Dr. Spencer Sealy of the Department of Zoology, University of Manitoba, conducted spring and fall banding of warblers moving through the narrow dune-forest along the south shore of Lake Manitoba. This area is an ideal location to mistnet migrant songbirds because it is bordered on one side by the lake and on the other by Delta Marsh. Migrants are thus likely to stop and move along this strip of forest before continuing on their way to the breeding or wintering grounds. The recent interest in the status of neotropical migrants by CWS and the willingness of Dr. S.G. Sealy and Heidi den Hann to collaborate in a follow-up study provided the necessary impetus for CWS's recent program established at the University Field Station at Delta Marsh.
In July 1992, with the assistance of Heidi den Haan who helped locate the positions of the mistnet sites she had used previously, we set up a three-year banding program. Several years of dormancy had left the sites a veritable jungle of nettles, burdock and willows, but in a few days the 12-metre nets were set up, ready to catch their first migrating songbirds. Paula Grieef and Enid Cumming, graduate students at the Universities of Manitoba and Saskatchewan, respectively, were hired to operate the station and, with the help of Marlene Gifford (University of Manitoba) and other volunteers, captured and banded over 3500 passerines between 15 July and 26 September. The resounding success of the operation occurred in spite of often poor weather conditions and the threat of predation of netted birds by foxes, hawks, and even white-tailed deer.

Highlights of this year's banding program included a Golden-winged 
Warbler (en route from Riding Mountain Park?), a male Black-throated Blue Warbler, a Yellow-throated Vireo and (believe it or not) a young Double-crested Cormorant. However, although these rarities are interesting, our main focus was on the more typical species to move through this site such as Ovenbird, Northern Waterthrush, American Redstart, and Yellow-rumped, Orange-crowned, Tennessee and Black-and-White warblers. In the years to come, we will be able to evaluate the status of these species with respect to their abundance a decade ago.

Following the end of the study in 1994 , it would also be extremely valuable to establish a permanent banding station at this site. Such a station would complement the other two permanent facilities in Saskatchewan and Alberta and provide valuable training and educational opportunities for graduate student and naturalist alike. The success of the Long Point Bird Observatory in southern Ontario attests to the effectiveness of involving volunteers and researchers in such a venture.

Our research program now established at Delta Marsh is a small step in an attempt to establish which of the songbirds are currently most at risk. Apart from a need for more ef- fective monitoring, more information is also needed on the habitat requirements and general ecology of many of our migrant songbirds. However, only through the interest and encouragement of the public will we see such monitoring and research supported and, with time running out for many of our songbirds, such public interest cannot come too soon.

1. ASKINS, R.A., J.F. LYNCH and R. GREENBERG. 1990. Population declines in migratory birds in eastern North America. Pp. 1-57 in D.M. Power (ed.) Current Ornithology Vol. 7. Plenum Publishing, New York.

2. BRITTINGHAM, M.C. and S.A. TEMPLE. 1983. Have cowbirds caused forest songbirds to decline? Bioscience 33:31-35.

3. DIAMOND, A.W. 1991. Assessment of the risks from tropical deforestation to Canadian songbirds. Trans. 56 N.A. Wildl. and Nat. Res. Conf.

4. ROBBINS, C.S., J.R. SAUER, R.S. GREENBERG and S. DROEGE. 1989. Population declines in North American birds that migrate to the neotropics. Proc. Natl. Acad. Sci. 86:7658-7662.

5. TERBORGH, J. 1989. Where have all the birds gone? Essays on the biology and conservation of birds that migrate to the American tropics. Princeton Univ. Press. 207 pp.

6. WILCOVE, D.S. 1985. Nest predation in forest tracts and the decline of migratory songbirds. Ecology 66:12111214.

May is the transition month, and exists to connect April and June, the root with the flower. John Burroughs. 1895. Wake Robin. Houghton Mifflin, Boston. 